\title{
Bilingual learners' willingness to communicate in English and anxiety when speaking the language
}

\author{
Olga Khudobina ${ }^{1, *}$, Olga Hopiaynen ${ }^{1}$ and Ekaterina Bondarenko ${ }^{2}$ \\ ${ }^{1}$ Department of foreign languages, Yugra State University, 16, Chekhova str., 628012, Khanty-Mansiysk, Russia \\ ${ }^{2}$ Department of Basic and Clinical Biochemistry, Volgograd State Medical University, 1, Pavshikh Bortsov Sq., 400131, Volgograd, \\ Russia
}

\begin{abstract}
The present study focuses on bilingual learners' willingness to communicate (WTC) in English and foreign language anxiety (FLA) when speaking English in the classroom at Yugra State University. The paper reviews the theory, experiment and methods of pedagogical correction for those who are interested in these two phenomena in their research. The aim of the paper is twofold: to identify the main communicational difficulties faced by learners, explore the underlying causes, and provide some recommendations to overcome learners' unwillingness to communicate in English actively and freely. The findings support the claims that FLA and WTC stem from issues with foreign language proficiency as well as some personal traits with FLA and WTC influencing each other and the process of mastering a second language.
\end{abstract}

\section{Introduction}

In recent decades considerable attention has been focused on topics related to bilingualism, second language learning and acquisition, resulting in a large number of publications. To meet the needs of Russian and international students, university authorities around the country have attempted to provide bilingual training - instruction aiming to provide expertise with the use of two languages as educational media or bilingualism as the final goal of education. This type of vocational training contributes to achieving a high level of communicative, professional and intercultural competencies by students; it also provides the best chances for their life and professional self-determination. However, effectiveness of bilingual education is ensured by an optimum choice of subject content, types of teaching programs and classroom techniques, models of bilingual education, as well as bilingual teachers' language awareness and willingness to communicate and teach in two languages. Both in Russia and abroad, there is still a shortage of bilingual teachers, and the process of their training is non-systemic and fragmented. Some educational institutions address their issues with the help of bilingual education putting forward their own target dominant; but at the global level there is no unity of goals, ideas, types of teaching programs, methods and techniques in particular; nor is there any holistic concept of vocational training of bilingual teachers as a whole.

A project to train bilingual teachers was initiated at Yugra State University in October 2018. Training of teachers was carried out in English language classes and was organized in an artificially created language environment which recreated, as accurately as possible, natural communicative situations in class, at a conference, in a hotel, at the airport, in a restaurant, etc. Based on the researchers' observations, foreign language learners often remained quiet in classroom activities, preferred to speak only with particular interlocutors, became nervous when English, spoke only when necessary, and they were always anxious about something. Considering that the process of learning any foreign language is stressful and difficult, it is important to explore the reticence and anxiety in learners in relation to many different aspects: poor English proficiency, low self-esteem, fear of speaking in front of others, shyness, lack of confidence, fear of making a mistake, etc. It is also necessary to enable people to perform successfully in a foreign language class, to overcome a mental block against learning and stimulate their willingness to communicate in English actively and freely.

\section{Problem statement}

Educators are interested in quantifying the effects of anxiety when learning a foreign language; they have offered different definitions of foreign language anxiety. Some of them, Clement, Young etc., define the term as a complex psychological construct, dealing with learners' psychology: their feelings, self-esteem, and selfconfidence associated mostly with language learning [13]. Guiora considers that the process of learning any foreign language itself is "a profoundly unsettling psychological proposition" because it directly threatens an individual's self-concept and worldview [4]. More specifically, E. K. Horwitz, M. B. Horwitz and Cope defined FLA as "a distinct complex construct of selfperceptions, beliefs, feelings, and behaviours related to

* Corresponding author: Olga hdb@mail.ru 
classroom language learning arising from the uniqueness of the language learning process" [5]. In this context, it is worth noting that they were the first who determined FLA as a unique type of anxiety that is specific to foreign language learning, as "a phenomenon related to but distinguishable from other specific anxieties" [6]. Similarly, MacIntyre and Gardner defined FLA as the feeling of tension and apprehension that the learner goes through in performing a learning task, including speaking, listening, and reading when using a foreign language $[7,8]$.

According to MacIntyre et al., the notion of willingness to communicate (WTC) is a state of readiness to speak freely, without fear at a particular time with a specific person or group of people using a foreign language. The degree of WTC depends on communicative context, personality traits, motivation for language learning, language proficiency etc., and indicates whether individuals choose to participate in communication or avoid joining a conversation. Different investigators like Kamprasertwong, Mahdi, Liu, Dewaele and others examined how personal factors (individual backgrounds, personality traits, communication strategies) influenced WTC and interacted with one another in English speech [9-14]. Other studies were conducted by Zarrinabadi, Addi, Barjesteh, Vaseghi, and Neissi [15, 16]. They investigated the relation between Iranian learners' willingness to communicate inside and outside the classroom and their language learning orientations. The authors concluded that language orientations correlated more closely with WTC outside rather than inside the classroom [11]. A study by Barjesteh et al. found that learners were willing to initiate communication in familiar situations, for example, when communicating with their friends; they were less willing to communicate in unfamiliar situations such as public speaking [16]. A study on Saudi students was conducted by Hamouda [17]. He defined the causes of non-participation of students in classroom activities in English; these were poor English proficiency, fear of speaking in front of others, shyness, lack of confidence and fear of making mistakes. More recently researchers have attempted to quantify the effects of anxiety on foreign language acquisition specifically associated with willingness to communicate in English in different classroom situations. According to McCroskey, Liu, Dewaele, AlSaraj, Yousef et al., Mahdi, willingness to communicate in English and language anxiety are strongly interrelated and connected with many other factors (individual, psychological, motivational etc.) so that they affect second language learning and communication [11-14, $18,19]$. Thus, this calls for a laborious search for most effective methods and completely new principles underlying the interaction of these factors.

\section{Objective of the study}

The objective of the present research is to investigate the main communication difficulties faced by learners (would-be teachers of international students) at Yugra
State University, to define the causes underlying these problems, and to suggest some solutions and recommendations to educators that can aid learners in overcoming major obstacles and demonstrating their willingness to communicate in English with ease and join the learning activities successfully.

\section{Research methods}

The data in the present study were gathered via questionnaires and interviews complementing each other. Eighty-five teachers participated in the project, and they were given a background questionnaire to elicit personal information about their age, gender, the number of languages they speak, motivation and reasons for language learning, etc. (see Appendix 1). The participants were also given a questionnaire to assess their proficiency in listening, speaking, reading and writing skills in English. For the purpose we used the International Program of the Council of Europe: "Learning languages by citizens of Europe" [20]. Additional evaluative data were collected in order to compare the information obtained from interviews and questionnaires with actual, real time occurrences in relation to the levels of their current language ability: Elementary: A1 - beginning speaker, A2 - early intermediate speaker; Intermediate: B1 - intermediate speaker, B2 - early advanced speaker; Advanced: C1 advanced speaker, $\mathrm{C} 2$ - proficient speaker.

To examine the score and severity of FLA, we used 33-item anxiety scale developed by Horwitz et al. [5]. To better fit the present study, the words "foreign languages" were replaced by "English". All the items with percentages of learners' answers were rated from strongly agree (SA) to strongly disagree (SD). Horwitz and her colleagues' theory of foreign language anxiety in second language acquisition has been widely accepted by researchers and has achieved the status of a precise and reliable tool [12]. The researchers also recorded what happened in class, and learners wrote their personal reflections on what they had experienced in classroom activities to provide their evaluation of and feedback on the project as a whole.

\section{Findings}

Of the 85 teachers informed of the language courses, only 35 indicated that they would like to join the groups in November 2018. Participation of teachers had to be limited to two groups of 12 students each due to time and other limitations. Diagnostics of learners was conducted by English language teachers. The results of the survey showed that half of the respondents (see Figure 1.) selfrated their level as that of a beginning speaker (50\%) while $25 \%$ and $22 \%$ rated themselves as early intermediate speaker $\mathrm{A} 2$ and intermediate speaker B1 respectively, and only $3 \%$ believed that they were ready to communicate in English fluently as B2 speakers. 


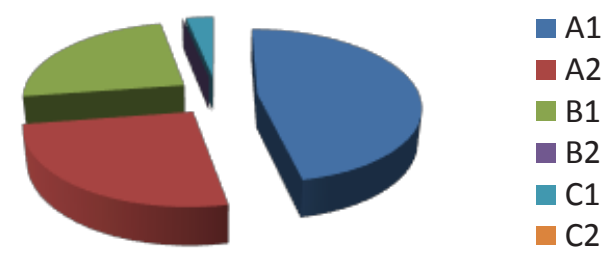

Fig.1. Self-rated proficiency in English

It is worth noting that testing conducted by English teachers revealed completely different results (see Fig. 2.), indicating that the project participants had inadequately overestimated their actual level of English proficiency. Thus, $92 \%$ of respondents had an initial level of English proficiency A1, and only $6 \%$ and $2 \%$ of participants had levels A2 and B1, respectively.

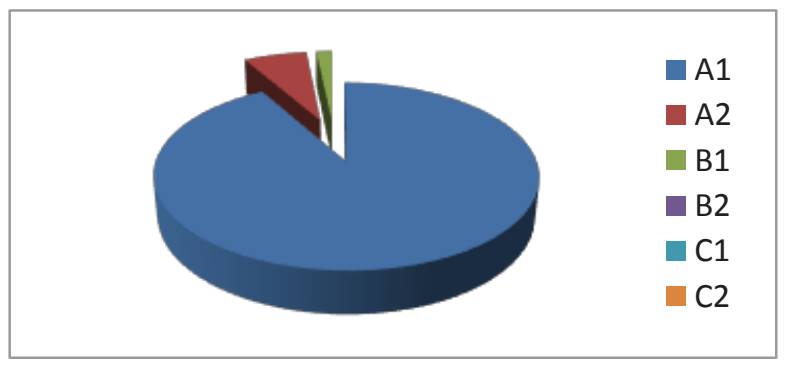

Fig.2. Proficiency in English rated by English teachers

This reflects learners' language incompetence in English thus highlighting the role of special languagesupportive methods and training programs in accordance with the determined levels of proficiency to assist in language learning.

The received data were also analyzed to identify the results the participants would like to achieve undertaking the English course. Of the 85 interviewees, $45 \%$ answered that they would be willing to communicate in English on tourist trips and journeys mainly because it might help them to improve their English for writing research papers and lectures (40\%), help them translate foreign literature in the original $(35 \%)$, improve self-confidence $(6 \%)$ and general expertise $(43 \%)$, take part in international conferences and events $(22 \%)$, make contacts with foreign colleagues (19\%); be involved in bilingual instruction of international students (7\%); improve their speech and oral skills (5\%). The data given are rounded to the nearest whole number. Percentages do not add to 100 due to the option of choosing several answers in response to one question. Thus, the presented results show that the learners were not willing to participate in classroom discussions, delivering lectures, communicating with international students etc., but they were willing to use English outside the university on various occasions such as in restaurants, in the street, in hotels, meeting new people, at international conferences etc. But as Meyer et al. state, deep learning and understanding cannot happen without appropriate academic language use [21].
According to observations made during the learning process the participants became silent, fearful and nervous. To obtain in-depth information, some interviews with the participants were conducted in the Russian language. The participants reported to have a 'kind of language block' against reading in English, and greater anxiety when speaking English, although they were strongly motivated to begin their course that month (in November 2018) and they said that they had used to perform well in the foreign language at school and university. The learners confessed that they were unable to express their thoughts and communicate their ideas. Their answers were as follows:

"I have been studying English for many years and I was quite sure that it would not be difficult for me to express my ideas, thoughts and feelings. But unfortunately, I cannot!"

"I know that English is the key to my success at work, but even though the teachers speak slowly and repeat several times, I have no idea of what they are saying, and it is difficult for me to ask follow-up questions."

"I have never been so nervous anywhere else as in my English class"

"The harder I work by myself, the more confused I get."

To examine the learners' level of anxiety when speaking English, we conducted an analysis using the English Language Anxiety Scale (ELAS) covering three following factors: low level of self-confidence in speaking English (S1), a general fear of different classroom activities (F2), anxiety about the English language class as it is (A3). Fourteen questions of thirty-three covered the first factor, ten ones - the second factor, and the rest of the questions concerned the anxiety about English classes in general. Responses to all items of the scale are reported in table 1 (see Appendix 2). Percentages are rounded to the nearest whole number. All the values refer to the number of students who agreed or strongly disagreed with the statements.

Learners defined English learning with the constructs "difficult" and "fear". They showed high on anxiety reporting that they were afraid of speaking in the second language. The learners chose ELAS items that were indicative of speech anxiety such as "I start to panic when I have to speak without preparation in my language class" $(\mathrm{SA}+\mathrm{A}=8+49=57 \%)$; "I get nervous and confused when I am speaking in my language class" (54\%). The participants also refused to accept the following propositions: "I feel very self-conscious about speaking English in front of other learners" $(\mathrm{D}+\mathrm{SD}=45+10=55 \%)$; "I would not be nervous speaking English with native speakers" (35\%). Anxious learners feel a deep fear when they are asked to communicate among other people and prefer to remain silent during the conversation. According to Horwitz et al., anxious students also apprehend that they will not be able to understand the speech of other students, teachers or native speakers [5]. Thus, the participants say that "they are nervous when they do not understand every word that was spoken" (37\%). Anxious students fear being laughed at by other students, and they are likely to feel 
anxious in different class activities. They are all adults perceiving themselves as intelligent and respectful people, so they want to avoid evaluative situations, and "the very expectation of being evaluated negatively" makes them nervous and disappointed. Unfortunately they believe that they will benefit more by keeping silence than by speaking in a variety of classroom situations. They stated, "I keep thinking that other students are better at languages than I am" (38\%), and disagree with "I do not worry about making mistakes in my language class" (51\%). They do not want to suffer humiliation when called on to communicate: "I tremble when I know that I'm going to be called on to speak in my English class" (48\%), but the learners are not afraid of written tests, they report, "I am usually at ease during English tests in class" (36\%). Besides, as Horwitz et al. note, anxious people are afraid of making mistakes and always accept every correction as a failure [5]. Learners' answers to the following items of the anxiety scale confirm the point of view that there exists a distinct language anxiety provoked by the uniqueness of foreign language learning. The participants complained about a large number of grammar rules they had to learn $(61 \%)$, they were more anxious and more highly strung in their English classes than in other ones (59\%). These results confirm that anxious students are not able to cope with the tasks of language learning. The findings get further support that foreign language anxiety is experienced by many learners as a majority of items (eighteen of thirty three) were confirmed by a half of participants. Nine of the first fourteen items (64\%) were supported by the learners, so the results suggest that at least half of the learners are not confident of speaking English in class. Learners surveyed also agreed with five statements out of ten $(50 \%)$, highlighting their fear and anxiety about a variety of language tasks. The rest four items of nine statements (44\%) were supported by the respondents as well expressing their specific anxiety in foreign language learning.

A study of the same group of learners focused also on links between motivation, willingness to speak English, real or true language proficiency, self-rated language proficiency and the level of anxiety. The present paper could not accommodate all the data due to its limited volume, but the most significant results were analyzed. The findings confirmed a negative correlation between current language proficiency estimated by English teachers, and the level of learners' anxiety. High levels of English language proficiency correlated positively with the willingness to communicate in English, and correlated negatively with high levels of anxiety. But it is noteworthy that the more confident of their language proficiency the learners were, the more worried they were about different classroom activities in particular and English language classes as a whole. These participants experienced a high level of language anxiety. Besides, high levels of motivation decreased anxiety, and high levels of anxiety abate motivation affecting the progress in the English language learning. These results may be mainly attributed to the following causes: (a) a contradiction between the aims of learning English and final outcomes the participants wanted to achieve at the end of the project, (b) inadequate learners' self-assessment of their language proficiency and some personality traits (lack of selfcriticism, arrogance, high self-esteem, overweening conceit etc.), (c) such personality traits as introversion, low self-esteem, lack of communicative competence, lack of confidence and alienation, (d) poor English proficiency, etc. Besides, as Horwitz et al. state language learning is a challenge that requires 'non-spontaneous mental operations in order to communicate well' and leads to reticence, fear or even panic [5].

Many attempts have been made by researchers to reveal the cause of language anxiety. Sparks and Ganschow note that "one cannot discuss anxiety without inferring a cause" [22]. Although they stress that anxiety can inhibit successful language learning, it is their point of view that anxiety is more likely to be a consequence rather than a cause of poor performance. In supporting Horwitz et al.' s position, MacIntyre opposes Sparks and Ganschow, indicating that anxiety causes difficulty with learning a foreign language, because even good and successful students show anxious reactions while learning, too $[7,22]$. It is a kind of 'chicken and egg' phenomenon: anxiety is the cause of students' failure and, at the same time, makes them feel fearful and tense. Thus, dealing with anxious students, we should introduce language-support methods and techniques to help learners cope with their blocks and open doors to effective learning.

\section{Pedagogical intervention}

Dealing with anxious students teachers should 1) make the language context less stressful, providing learners with interesting collaborative instruction; 2) implement language support methods and techniques; 3) establish a rapport with learners encouraging their reassurance; 4) monitor and identify the sources of learner's fear and anxiety; 5) work out a system of optimal difficulties, improving the level of language proficiency and stimulating personal development as well.

Changing the content of foreign language learning is an important task. As the process of learning a foreign language takes place in a formal university setting, it is necessary to choose the topics that make learners speak freely and participate actively. The findings of questionnaires and interviews have demonstrated that learners prefer to speak English more in interpersonal communication discussing such topics as travelling, holidays, places of attraction, traditions, cultural similarities and differences, cuisines of different countries etc., than in other types of contexts such as public speaking and formal meetings. Thus, one of the tasks of the teacher is to introduce learning material (grammar, phonetics, writing etc.) by the example of specified topics at least in the first classes at the university level. With the help of these simple and 
cheerful discussions, short dialogues and role plays on favourite and familiar topics, it is important for English educators to help students overcome their fear of speaking in public. During class activities, the teacher should select tasks in accordance with individual learners' fears and levels of their language anxiety and work out a system of language barriers of optimal difficulty. But a more difficult task is to create these optimal language barriers - the obstacles that would enhance students' willingness to communicate in English, the obstacle that would help students to overcome language blocks and increase the overall emotional satisfaction with the learning process as well. A more important thing for the instructor is to acknowledge the existence of anxiety reactions (fear, tension, indifference, reticence, poor performance, panic, frustration, etc.) so as to do their best to implement language-support methods and techniques to reduce stress and fear. The instructor should allow students, who are afraid of communicating in English in public, to assume the role of a leader in a small group and then guide them slowly but regularly to speak in larger groups, preparing the learner to debate and deliver successful presentations at subsequent conferences and lectures. What is also worth noting during this process of learning is that the teacher should not focus on students' mistakes but should rather be a supportive facilitator providing positive responses and guidance.

During the project there were also implemented some bilingual language support techniques of visual support, reading support, language support, and some bilingual tools of "language input", "prompting", "code switching", etc. The method of visual support involves the use of drawings, photographs, tables, diagrams, films, videos and presentations in the learning process to have a reinforcing effect on retention [23]. Banks notes that "students learn better if they see and hear words in the target language. ... The challenge to language instructors is to devise ways of augmenting their verbal presentations with non-verbal visual material". Methods of language support imply the use of cues and prompts aiming to help students in the process of generating oral and written utterances, as well as articulating their knowledge and expressing their thoughts and findings appropriately [24]. The prompts are plans, questions, key words and word combinations, symbols, numerals, etc. Developing spoken language skills, it is important to teach learners to find the clues and use them, for example, for role playing a dialogue with a gradual release from the prompts. Code switching is alternating two languages in the learning process. The method plays a positive role in language development of learners and presents a form of communicative support to expand their language competency $[25,26]$. Code switching can be used as a tool to build terminology in two languages; to fill in lexical gaps; to conduct comparative analysis; for psychological reasons, to reduce the students' level of anxiety.
A complex mix of attraction tools may also contribute to greater willingness to communicate in English and can lead to lower anxiety. They are: mirror of relationships, a specific tool implemented through visual contact, smile, arrangement of supportive learning atmosphere in class etc.; golden words, the use of compliments, praise and pleasant words to increase learners' self-confidence and stimulate further learning; emotional echo: infecting others with your good mood and positive attitudes to learning English; empathy - the ability to respond emotionally to another person's psychological state, to rejoice at someone else's joy and sympathize with someone else's grief, to display trust and sympathy; the tool of endorsement expresses one's approval for the learner's performance and achievements with the use of encouraging smile and words etc.

Humour takes a special place among the methods of attraction in classroom activities. Humour allows students to maintain self-control and reduce feelings of tension and internal discomfort. Humour is one of the ways that allows people to shift focus from negative and unpleasant experience to positive and stimulating situations helping to inhibit high levels of anxiety. With the help of humour such as a metaphor, funny story and improvisation or a joke, learners can not only develop willingness to speak a foreign language and decrease anxiety, but also activate their mental activity. Thus, for example, when learners are delivering presentations, the instructor should begin with mock presentations by student volunteers [11]. The instructor asks learners to make their own dialogues and then while role playing, asks them to change the content of the dialogues in any funny way. As a result smiles, humour and vivid cheerful improvisations make learners forget their feeling of tension and nervousness, and perform successfully in a foreign language class without preparation and any fear of making a mistake.

\section{Conclusion}

The present research has shown that many learners were willing to speak English because it was beneficial to them. For example, doing so could help them to improve their oral skills and enhance general expertise. In terms of anxiety, most participants reported being anxious when speaking English in the class. Only three interviewees reported no anxiety when speaking a foreign language in class due to their high level of English proficiency or passion for learning foreign languages. If the learners were not willing to communicate in English, they attributed it to the following causes: being introverted and unconfident, poor English proficiency, fear of being unable to speak well, serious worry about English classes etc. Further analyses of the causes indicate that some of them were specific to the present situation such as a conflict between the aims of learning English, and final outcomes the 
participants wanted to achieve by the end of the project as well as inadequate self-assessment of their language proficiency. Thus, there is an interrelation between willingness to speak English and foreign language anxiety; their reciprocal influence plays an important role in the process of language learning and acquisition.

Evidently, to improve learners' competence in English educators must first acknowledge the existence of foreign language anxiety trying to be highly attentive to its negative effects such as learners' reticence and panic, being unprepared, indifferent and forgetful, avoidance of classroom activities, poor performance, low motivation, difficulty in concentrating, skipping classes, sweating and so on. Secondly, English teachers can help learners to cope with the existing anxiety-provoking situation, making the learning context less stressful and using a mix of effective educational methods and techniques. An optimal choice of bilingual language support methods and attraction tools contributes to development of English proficiency and allays learners' anxiety. To sum up, dealing with the problems under study English teachers should become supportive facilitators and sympathetic listeners rather than strict and insistent educators so as to decrease anxiety and boost learners' willingness to speak English.

The current study shows to what extent language anxiety influences the willingness to speak English, and the progress in language acquisition. It has confirmed that FLA is a complex phenomenon and distinctive from other forms of anxiety. It has become clear that foreign language learning has a greater potential of frustrating learners' physical condition and challenging their selfconfidence and identity than any other learning activities, and the process is likely to be the focus of research interest.

\section{References}

1. R. Clement, S.C. Baker, P.D. MacIntyre, Journal of Language and Social Psychology 22, 190-209 (2003)

2. D.J. Young, Faces in a crowd: The individual learner in multisection courses. (Boston: Heinle and Heinle Publishers, 3-46, 1994)

3. D.J. Young, Georgetown University Round Table on Languages and Linguistics, 398-411 (1995)

4. A.Z. Guiora, Language Learning 33, 3 - 12 (1983)

5. E.K. Horwitz, M.B. Horwitz, J.A. Cope, The Modern Language Journal 70(2), 125-132 (1986)

6. Tran Thi Thu Trang, English Language Learning, 5(1) (2012)

7. P.D. MacIntyre, Language Anxiety: A Review of the Research for Language Teachers, (Boston: McGrawHill, 1998)

8. P.D. MacIntyre, R. C. Gardner, Language Learning, 44(2), 283-305 (1994)

9. P.D. MacIntyre, R.C. Gardner, Studies in Second Language Acquisition 16, 1-17 (1994)

10. M. Kamprasertwong, Willingness to communicate in English speech as a second language: A study of Thai, Chinese, and Dutch samples (Unpublished M. A. Thesis, Groningen: University of Groningen, Netherlands, 2010)
11. A.D. Mahdi, English Language Teaching, 7(7), 17-25 (2014)

12. M.Liu, International Journal of Bilingual Education and Bilingualism, 21(1), 54-69 (2018)

13. Jean-Marc Dewaele, The Modern Language Journal 97(3), 670-684 (2013)

14. Jean-Marc Dewaele, M. Al-Saraj Taghreed, Studies in Second Language Learning and Teaching 5, 205-208 (2015)

15. N. Zarrinabadi, R. Abdi, International Education Studies 4(4), 206-214 (2011)

16. H. Barjesteh, R. Vaseghi, S. Neissi, International Journal of English Linguistics 2, 47-54 (2012)

17. A. Hamouda, International Journal of English Language Education 1, 17-34 (2013)

18. J.C. McCroskey, A. Sallinen-Kuparinen, V. P. Richmond, Communication Research Reports 8, 55-64 (1991)

19. R. Yousef, H. Jamil, N. Razak, English Language Teaching 6(9), 205-216 (2013)

20. Council of Europe, Common European Framework of Reference for Languages: Learning, Teaching, Assessment (Cambridge University Press, 2001)

21. O. Meyer, D. Coyle, A. Halbach, K. Schuck, and T. Ting, Language, Culture and Curriculum 28(1), 41-57 (2015)

22. R.L. Sparks, L. Ganschow, The Modern Language Journal 79(2), 235-244 (1995).

23. O.F. Khudobina, I.N. Fedulov, E.V. Bondarenko, SHS Web of Conferences-CILDIAH-2018 50, 01078 (2018)

24. Banks, T. Foreign language learning difficulties and teaching Strategies (School of Education Dominican University of California, San Rafael, CA, 2008)

25. W. Quin Yow, J. S. H. Tan, Bilingualism: Language and Cognition 21(5), 1075-1090 (2018)

26. N.H. Hornberger, H. Link, International Journal of Bilingual Education and Bilingualism 15, 261-278 (2012)

\section{Appendix 1. A background questionnaire for participants of the project.}

Instruction: Please write down your responses to the following questions:

1 . What is your full name?

2. What is your age?

3. What is your gender? (Male/female)

4. What languages do you speak?

5. Do you speak English at work?

6. Are you learning English now?

7. How many hours a week can you allocate in your work schedule for learning English?

8. When are you ready to start learning English?

9. What are the reasons motivating you to learn English?

10. What results would you like to achieve undertaking the English course?

Appendix 2. The EIAS items with percentages of participants' responses. 


\begin{tabular}{|c|c|c|c|c|}
\hline \multicolumn{5}{|c|}{$\begin{array}{c}\text { The English Language Anxiety Scale/ percentages } \\
\text { learners choosing each item }\end{array}$} \\
\hline SA & $\mathrm{A}$ & $\mathrm{N}$ & $\mathrm{D}$ & SD \\
\hline \multicolumn{5}{|c|}{$\begin{array}{l}\text { 1. I never feel quite sure of myself when I am } \\
\text { speaking English in my class. }\end{array}$} \\
\hline 10 & 48 & 12 & 20 & 10 \\
\hline
\end{tabular}

2. I would probably feel comfortable around native speakers of English.

\begin{tabular}{|l|c|c|c|c|}
\hline 9 & 20 & 20 & 40 & 11 \\
\hline $\begin{array}{l}\text { 3. I don't worry about making mistakes in the English } \\
\text { class. }\end{array}$ \\
\hline
\end{tabular}
class.

\begin{tabular}{l|l|l|l|l}
9 & 12 & 28 & 43 & 8 \\
\hline
\end{tabular}

4. I would not be nervous speaking English with native speakers.

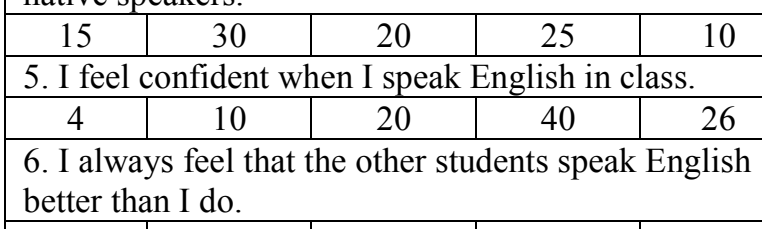

\begin{tabular}{|c|c|c|c|c|}
\hline 13 & 22 & 21 & 28 & 16 \\
\hline \multirow{2}{*}{\multicolumn{5}{|c|}{$\begin{array}{l}\text { 7. I worry about the consequences of failing my } \\
\text { English class. }\end{array}$}} \\
\hline & & & 20 & 12 \\
\hline
\end{tabular}

8. I am afraid that the other students will laugh at me when I speak English.

\begin{tabular}{c|c|c|c|c}
8 & 12 & 26 & 28 & 26 \\
\hline
\end{tabular}

9. I feel very self-conscious about speaking English in front of other students.

\begin{tabular}{l|l|l|l|l}
10 & 15 & 30 & 45 & 10
\end{tabular}

10. I don't feel pressure to prepare very well for the English class.

\begin{tabular}{|l|l|l|l|l}
20 & 20 & 30 & 22 & 8 \\
\hline
\end{tabular}

11. I start to panic when I have to speak without preparation in the English class.

\begin{tabular}{|c|c|c|c|c|}
\hline 8 & 49 & 26 & 12 & 5 \\
\hline 12. I get nervous and confused when I am speaking \\
English in class. \\
\hline 11 & 43 & 22 & 15 & 9 \\
\hline
\end{tabular}

13. It embarrasses me to volunteer answers in my English class.

\begin{tabular}{|c|c|c|c|c|}
\hline 20 & 42 & 10 & 18 & 10 \\
\hline \multicolumn{5}{|c|}{$\begin{array}{l}\text { 14. I am afraid that my English teacher is ready to } \\
\text { correct every mistake I make. }\end{array}$} \\
\hline 10 & 20 & 27 & 23 & 20 \\
\hline \multicolumn{5}{|c|}{$\begin{array}{l}\text { 15. I am usually at ease during English tests in my } \\
\text { class. }\end{array}$} \\
\hline 4 & 32 & 38 & 13 & 13 \\
\hline \multicolumn{5}{|c|}{$\begin{array}{l}\text { 16. The more I study for an English test, the more } \\
\text { confused I get. }\end{array}$} \\
\hline 20 & 38 & 20 & 12 & 10 \\
\hline
\end{tabular}

\begin{tabular}{|l|l|l|l|l|}
\hline 25 & 23 & 10 & 22 & 20 \\
\hline
\end{tabular}

18. It frightens me when I don't understand what the teacher is saying in English.

\begin{tabular}{l|l|l|l|l}
13 & 39 & 20 & 15 & 13
\end{tabular}

19. I get upset when I don't understand what the teacher is correcting.

\begin{tabular}{|c|c|c|c|c|}
\hline 8 & 43 & 18 & 24 & 7 \\
\hline
\end{tabular}

20. I get nervous when the English teacher asks questions which I haven't prepared in advance.

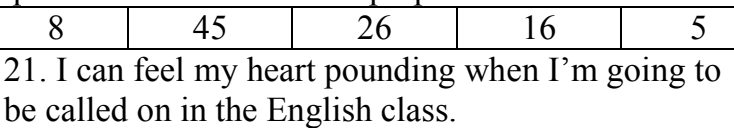

\begin{tabular}{|c|c|c|c|c|}
\hline 5 & 23 & 19 & 36 & 17 \\
\hline
\end{tabular}

22. I keep thinking that the other students are better at English than I am.

\begin{tabular}{l|l|l|l|l}
14 & 24 & 26 & 23 & 13 \\
\hline
\end{tabular}

23. Even if I am well prepared for the English class, I feel anxious about it.

\begin{tabular}{|l|l|l|l|l}
7 & 36 & 23 & 26 & 8 \\
\hline
\end{tabular}

24. During my English class, I find myself thinking about things that have nothing to do with the course.

\begin{tabular}{|c|c|c|c|c|}
\hline 8 & 11 & 30 & 37 & 14 \\
\hline
\end{tabular}

25. I often feel like not going to my English class.

\begin{tabular}{|c|c|c|c|c|}
\hline 5 & 14 & 24 & 37 & 20 \\
\hline
\end{tabular}

26. When I'm on my way to the English class, I feel very sure and relaxed.

\begin{tabular}{|c|c|c|c|c|}
\hline 9 & 15 & 23 & 46 & 7 \\
\hline
\end{tabular}

27. It wouldn't bother me at all to take more foreign language classes.

\begin{tabular}{l|l|l|l|l}
15 & 21 & 17 & 38 & 9
\end{tabular}

28. I feel more tense and nervous in my English class than in my other classes

\begin{tabular}{|c|c|c|c|c|}
\hline 16 & 43 & 17 & 15 & 9 \\
\hline 29
\end{tabular}
over English classes.

\begin{tabular}{|c|c|c|c|c}
7 & 18 & 32 & 36 & 7 \\
\hline
\end{tabular}

30. I feel overwhelmed by the number of rules I have to learn to speak English.

\begin{tabular}{|c|c|c|c|c|}
\hline 7 & 43 & 27 & 13 & 10 \\
\hline
\end{tabular}

31. English class moves so quickly I worry about getting left behind.

\begin{tabular}{|c|c|c|c|c}
\hline 12 & 17 & 23 & 26 & 22 \\
\hline
\end{tabular}

32. In the English class, I can get so nervous I forget things I know.

\begin{tabular}{|l|c|c|c|c|}
\hline 8 & 12 & 22 & 49 & 9 \\
\hline \begin{tabular}{|l} 
33. I get nervous when I don't understand every word \\
the English teacher says.
\end{tabular} \\
\hline
\end{tabular}

\begin{tabular}{|c|c|c|c|c|}
\hline 17 & 20 & 26 & 24 & 13 \\
\hline
\end{tabular}

SA- strongly agree; A - agree; N- neither agree nor disagree; D - disagree; $\mathrm{SD}$ - strongly disagree. 